Fernando Suparregui Dias ${ }^{1}$, Clarice Sampaio Alho², Caroline Schwartz Henkin $^{3}$, Juliano Cé Coelho ${ }^{3}$, Mateus Chissini Paganella ${ }^{3}$, Rodrigo Morais de Siqueira ${ }^{3}$, Fernanda Stringhi ${ }^{4}$, Michelle Eidt ${ }^{4}$, Virgínia Távora ${ }^{5}$

1. Professor da Faculdade de Medicina da Pontifícia Universidade Católica do Rio Grande do Sul - PUCRS - Porto Alegre (RS), Brasil.

2. Doutora, Professora da Faculdade de Biociências da Pontifícia Universidade Católica do Rio Grande do Sul PUCRS - Porto Alegre (RS), Brasil. 3. Acadêmico da Faculdade de Medicina da Pontifícia Universidade Católica do Rio Grande do Sul - PUCRS - Porto Alegre (RS), Brasil.

4. Médica Residente de Medicina Interna do Hospital São Lucas da Pontifícia Universidade Católica do Rio Grande do Sul - PUCRS - Porto Alegre (RS), Brasil.

5. Médico da Unidade de Terapia Intensiva Geral do Hospital São Lucas da Pontifícia Universidade Católica do Rio Grande do Sul - PUCRS - Porto Alegre (RS), Brasil.

Recebido da Faculdade de Medicina da Pontifícia Universidade Católica do Rio Grande do Sul - PUCRS - Porto Alegre (RS), Brasil.

Submetido em 30 de Abril de 2009 Aceito em 23 de Dezembro de 2009

Autor para correspondência:

Fernando Suparregui Dias

Av. Ipiranga 6690 - Conj. 620 - Jardim Botânico

CEP: 90610-000 - Porto Alegre (RS), Brasil.

Fone/Fax: (51) 3336-0304

E-mail: fersdias@via-rs.net

\section{Suscetibilidade genética na lesáo pulmonar aguda e síndrome da angústia respiratória aguda}

\author{
Genetic susceptibility in acute lung injury and acute respiratory \\ distress syndrome
}

\section{RESUMO}

A lesão pulmonar aguda e sua forma mais grave, a síndrome da angústia respiratória aguda, são o denominador comum de várias doenças que podem provocar uma inflamaçáo exagerada nos pulmôes. Nos últimos anos, essa variabilidade tem sido atribuída, pelo menos em parte, a fatores genéticos. O presente estudo tem por objetivos revisar o papel dos principais genes envolvidos na suscetibilidade, morbidade e mortalidade na lesão pulmonar aguda e na síndrome da angústia respiratória aguda. Através de pesquisa nas bases de dados PubMed e LiLACS, empregando-se os unitermos lesão pulmonar aguda, síndrome da angústia respiratória aguda e síndrome da angústia respiratória do adulto em combinaçáo com polimorfismos genéticos, foram selecionados 69 artigos, dos quais 38 foram incluídos nesta revisão. Foram tam-

\begin{abstract}
bém considerados artigos relevantes extraídos das referências bibliográficas nos artigos selecionados das bases de dados. Os polimorfismos genéticos são variantes gênicas presentes em pelo menos $1 \%$ da populaçáo. A presença destas variantes genéticas pode influenciar a expressão de mediadores da resposta inflamatória, afetando diretamente a suscetibilidade à lesão pulmonar aguda, a intensidade da inflamação no parênquima pulmonar, a evolução e o desfecho destes pacientes. Estudos de associação com grandes populaçóes e passíveis de reprodução permitiráo de modo definitivo a inclusáo da genômica no arsenal diagnóstico, prognóstico e terapêutico de pacientes com lesão pulmonar aguda/síndrome da angústia respiratória aguda
\end{abstract}

Descritores: Lesão pulmonar; Síndrome da angústia respiratória do adulto; Polimorfismo genético

\section{INTRODUÇÃO}

A lesão pulmonar aguda (LPA) e a sua expressão maior, a síndrome de desconforto respiratório agudo (SDRA), são o denominador comum de uma gama de doenças que podem desencadear resposta inflamatória pulmonar intensa. Estes fatores são considerados primários quando a lesão pulmonar inicia-se no lado epitelial e secundários quando se inicia no lado endotelial da barreira alvéolo-capilar. ${ }^{(1,2)}$

Estudos epidemiológicos mostram uma variabilidade considerável na incidência de LPA/SDRA, estimando-se que o número de casos por 100.000 habitantes por ano seja 78,9 nos Estados Unidos da América (EUA), ${ }^{(3)} 13,5$ na Escandinávia, ${ }^{(4)} 16$ na Escócia ${ }^{(5)}$ e 28 na Austrália. ${ }^{(6)}$ Embora vários fatores de risco possam desencadear a síndrome, ${ }^{(1,2)}$ sua expressão e mortalidade atribuída são muito variáveis. ${ }^{(7)}$ Um dos motivos para explicar essas diferenças pode ser justamente o impacto dos diferentes fatores de risco na expressão da resposta inflamatória. ${ }^{(8)}$

Nos últimos anos, vários estudos no campo da genômica têm mostrado associação entre doença crítica e determinantes genéticos, o que levou a um conhecimento mais 
aprofundado dos mecanismos fisiopatológicos, em particular na sepse/choque séptico e LPA/SDRA. Uma questão importante na LPA e na SDRA é por que alguns pacientes morrem como resultado de uma inflamaçáo descontrolada ou por sepse, enquanto outros se recuperam sem maiores problemas. Isto poderia ser explicado, ao menos em parte, pelo fato de que os eventos celulares envolvidos na mediação da inflamação, na lesão tecidual e no reparo, são controlados em nível molecular, não podendo ser totalmente explicados sem se considerar a funçáo dos genes participantes nesta resposta e seus produtos. ${ }^{(9)}$ Em estudos experimentais, por exemplo, foi demonstrado que a expressáo do perfil genético na lesão pulmonar é específica para o tipo de lesão. Em modelo com ratos, dos Santos et al. ${ }^{(10)}$ documentaram que a expressão de genes na LPA induzida pelo LPS é diferente da induzida pela hiperdistensão alveolar. Esta alteraçáo ocorre precocemente na lesão induzida pela ventilação mecânica com volume corrente elevado e causa a expressão de genes de mediadores pró-inflamatórios. ${ }^{(11)}$ Existem evidências de que a resposta imune humoral e celular é objeto de controle genético polimórfico, o que poderia explicar a diversidade de manifestaçóes, desfechos e de risco de tornar-se crônica entre pacientes com a mesma doença. Isso se deve a polimorfismos gênicos, os quais são variantes de genes, em pelo menos $1 \%$ da populaçáo. ${ }^{(12)}$

$\mathrm{Na}$ LPA/SDRA inúmeros genes candidatos foram associados à suscetibilidade, evolução e desfechos. O papel desses genes está relacionado à inflamação, resposta imune, permeabilidade vascular, tônus vascular, reparo, quimiotaxia, motilidade celular e coagulação (Quadro 1). Do ponto de vista

Quadro 1 - Genes associados à lesão pulmonar aguda/síndrome da angústia respiratória aguda

\begin{tabular}{|c|c|c|c|}
\hline Autor & Gene & Polimorfismo & Associação na LPA/SDRA \\
\hline \multirow[t]{2}{*}{ Gong $\mathrm{MN}$, et al. ${ }^{(17)}$} & FNT- $\alpha$ & $-308 \mathrm{G}>\mathrm{A}$ & $\uparrow$ mortalidade \\
\hline & FNT- $\beta$ & FNTB12 & Não afeta a mortalidade \\
\hline Flores C, et al. ${ }^{(19)}$ & IL-6 & $\begin{array}{l}\text { seis SNPs de }-1363 \mathrm{a}+4835 \text { do } \\
\text { 5' IL-6 gene }\end{array}$ & Haplótipo GGGAAC $\uparrow$ suscetibilidade \\
\hline Hildebrand F, et al. ${ }^{(21)}$ & IL-8 & $-251 \mathrm{~A}>\mathrm{T}$ & $\uparrow$ tempo VM \\
\hline Gong MN, et al. ${ }^{(23)}$ & IL-10 & $-1082 \mathrm{G}>\mathrm{A}$ & $\begin{array}{l}\text { Genótipo GG } \uparrow \text { suscetibilidade em idade }<52 \text { anos } \\
\downarrow \text { DMOS e mortalidade } 60 \text { dias }\end{array}$ \\
\hline Schroeder O, et al. ${ }^{(22)}$ & IL-10 & $-1082 \mathrm{G}>\mathrm{A}$ & $\downarrow$ suscetibilidade \\
\hline Gong MN, et al. ${ }^{(27)}$ & MBL-2 & SNPs nos codons $52,54,57$ & $\begin{array}{l}\text { homozigotos } 54 \mathrm{BB} \uparrow \text { suscetibilidade, gravidade, } \\
\text { DMOS e mortalidade }\end{array}$ \\
\hline Gao L, et al. ${ }^{(28)}$ & $\begin{array}{l}\text { Myosin light chain } \\
\text { kinase }(M Y L K)\end{array}$ & 51 SNPs & $\begin{array}{l}\text { haplotipos específicos à 5' e à 3' do gene em diferentes } \\
\text { populaçóes } \uparrow \text { suscetibilidade }\end{array}$ \\
\hline \multirow[t]{2}{*}{ Bajwa EK, et al. ${ }^{(31)}$} & PBEF & $-1001 \mathrm{G}>\mathrm{T}$ & $-1001 \mathrm{G}>\mathrm{T} \uparrow$ suscetibilidade \\
\hline & & $-1543 \mathrm{~T}>\mathrm{C}$ & $-1543 \mathrm{~T}>\mathrm{C}$ melhor desfecho \\
\hline Zhai R, et al. ${ }^{(33)}$ & $\mathrm{I} \kappa \mathrm{B}-\alpha$ & $\begin{array}{l}-881 \mathrm{~A}>\mathrm{G},-826 \mathrm{C}>\mathrm{T}, \\
-297 \mathrm{C}>\mathrm{T}\end{array}$ & $\begin{array}{l}\text { Haplótipo GTC } \uparrow \text { risco de SDRA em caucasianos, par- } \\
\text { ticularmente do sexo masculino }\end{array}$ \\
\hline \multirow[t]{2}{*}{ Adamzik M, et al. ${ }^{(34)}$} & NFKB1 & I/D -94ATTG & Afeta a gravidade da LPA \\
\hline & & & Não afeta a mortalidade \\
\hline Arcaroli JJ, et al. ${ }^{(36)}$ & EC-SOD & $\begin{array}{l}\text { rs } 4691, \text { rs } 5321, \text { rs } 5360 \\
\text { rs } 5955, \text { rs } 5982\end{array}$ & Haplótipo GCCT $\downarrow$ LPA e a mortalidade \\
\hline Arcaroli JJ, et al. ${ }^{(38)}$ & Urokinase & $\begin{array}{l}\text { rs2227562, rs2227564, } \\
\text { rs2227566, rs2227571, rs4065 }\end{array}$ & $\begin{array}{l}\text { Haplótipo CGCCCC Fator de risco } \uparrow \text { mortalidade } \\
\uparrow \text { tempo de VM }\end{array}$ \\
\hline Adamzik M, et al. ${ }^{(39)}$ & Fator V de Leiden & $\operatorname{Arg} 506 \mathrm{Gln}$ & Mortalidade $\downarrow$ em heterozigotos \\
\hline Marshall MP, et al. ${ }^{(41)}$ & ECA & $\mathrm{I} / \mathrm{D}$ & Alelo D associa-se com suscetibilidade e mortalidade \\
\hline Jerng JS, et al. ${ }^{(43)}$ & ECA & $\mathrm{I} / \mathrm{D}$ & $\begin{array}{l}\text { Genótipo II melhor chance de sobrevida; alelo D não } \\
\text { associa-se a } \uparrow \text { da mortalidade em chineses }\end{array}$ \\
\hline Villar J, et al. ${ }^{(44)}$ & ECA & $\mathrm{I} / \mathrm{D}$ & Sem associação a suscetibilidade ou mortalidade na SDRA \\
\hline \multirow[t]{2}{*}{ Adamzik M, et al. ${ }^{(42)}$} & ECA & $\mathrm{I} / \mathrm{D}$ & Genótipo DD $\uparrow$ risco de morte \\
\hline & & AGT $-6 A>G$ & AGT $-6 A>G$ não altera susceptibilidade ou mortalidade \\
\hline Medford AR, et al. ${ }^{(45)}$ & VEGF & $936 \mathrm{C}>\mathrm{T}$ & $\begin{array}{l}\text { Genótipos CT e TT são mais frequentes e associados a } \\
\text { risco de morte na SDRA }\end{array}$ \\
\hline Gong $\mathrm{MN}$, et al. ${ }^{(46)}$ & SFTPB & SNP no intron 4 & $\begin{array}{l}\text { 个 suscetibilidade em mulheres } \\
\uparrow \text { LPA primária em mulheres }\end{array}$ \\
\hline Lin Z, et al. ${ }^{(47)}$ & $\begin{array}{l}\text { SP-A1, SP-A2, } \\
\text { SP-B, SP-D }\end{array}$ & SP-B Thr13Ile & $\uparrow$ suscetibilidade de SDRA \\
\hline Frerking I, et al. ${ }^{(48)}$ & CC16 & $-26 \mathrm{G}>\mathrm{A}$ & Não afeta a suscetibilidade ou desfecho \\
\hline
\end{tabular}

LPA = lesão pulmonar aguda; SDRA = síndrome de desconforto respiratório agudo. 
prático, interessa ao intensivista saber se um marcador genético pode identificar alguns aspectos tais como quais pacientes seriam mais suscetiveis a desenvolver LPA/SDRA, quais podem responder melhor a um determinado tratamento e qual será o prognóstico de um paciente em particular. ${ }^{(7)}$

Levando-se em conta o fato de que a LPA/SDRA é consequência de outras doenças, cursa com mortalidade elevada, impóem ao paciente uma recuperação demorada e consome consideráveis recursos econômicos, o presente estudo tem por objetivo revisar os principais genes e suas variantes polimórficas associadas com a incidência, morbidade e mortalidade atribuída à LPA/SDRA.

A base da revisão bibliográfica foram artigos do PubMed (National Library of Medicine and National Institute of Health - USA), da LiLACS e referências relevantes citadas nos artigos extraídos da pesquisa. A busca foi feita utilizando-se os descritores lesão pulmonar aguda, síndrome da angústia respiratória aguda e síndrome da angústia respiratória do adulto, em combinação com polimorfismos genéticos, considerando-se apenas pacientes adultos. Foram identificados 69 artigos, entre os quais, após a exclusão de editoriais, revisóes e estudos de polimorfismos genéticos em outras patologias, restaram 38 estudos, incluídos nesta revisão. Foram também considerados artigos relevantes extraídos das referências bibliográficas nos artigos selecionados das bases de dados.

\section{ESTUDOS DE ASSOCIAÇÃO DE GENES CANDI- DATOS E LPA/SDRA}

Como a LPA/SDRA não são dependentes de um único fator etiológico, representam um desafio para os estudos de associaçâo genômica. Os principais objetivos de identificarem-se marcadores genéticos nesta síndrome consistem na determinação da suscetibilidade para sua ocorrência, na determinação do prognóstico e na identificação de quais pacientes podem beneficiar-se com determinado tratamento. (7) A conclusão da seqüência do genoma humano catalogou mais de 1.4 milhóes de polimorfismos de um nucleotídeo único (SNP - single nucleotide polymorphism), com a maioria das variaçóes ocorrendo em regióes do genoma que não codificam para produtos protéicos. ${ }^{(13)} \mathrm{Um}$ SNP é uma alteração no DNA que representa a variaçáo em uma única base e é usado para descrever a variação genética entre os indivíduos. ${ }^{(7)}$ Quando estes SNPs ocorrem em regiōes que codificam proteínas, podem afetar a função ou a eficiência desta proteína ou de um gene. ${ }^{(14)}$

O estudo da expressão e função de um gene através da análise de seu fenótipo é útil em doenças genéticas com a clássica herança mendeliana. Na LPA/SDRA este método não é adequado, já que existem múltiplas interaçóes de diferentes genes e inúmeros fatores de risco. Em virtude dessa dificuldade, os estudos de caso-controle com genes candidatos são a abordagem mais comum na pesquisa de fatores relacionados à suscetibilidade da LPA/SDRA. Nesses estudos, uma variante genética tem seu genótipo determinado em uma população onde se dispóem da informação fenotípica (LPA/SDRA). Havendo correlação entre o genótipo em estudo e o fenótipo, assume-se que exista associação entre a variante genética e a doença. ${ }^{(7)}$

Uma outra maneira para se identificar genes candidatos é através da técnica de microarrays. Esta técnica determina o grau de expressão de um gene através da mensuração do mRNA (ácido ribonucleico mensageiro). Resumidamente, consiste na preparação de recipiente para o DNA dos genes de interesse, seguindo o esquema: (1) isolamento do mRNA das células de um tecido; (2) geração de cDNA através de transcrição reversa; (3) hibridização do cDNA com o DNA do array; (4) geração de imagens do array através de digitalização óptica com o uso de laser. ${ }^{(15)}$ Entretanto, pelo fato da LPA/SDRA ser uma entidade complexa, as alteraçóes em genes específicos provavelmente náo explicam todos os distúrbios fisiológicos completamente. A ampla variabilidade fenotípica, a penetrância incompleta, as interaçóes decorrentes da genética com o meio e o potencial para heterogeneidade nos locus, tornam a avaliação genética desta síndrome difícil. ${ }^{(16)}$ Além do mais, não há a possibilidade de se isolar células do tecido afetado durante o curso da LPA/SDRA a fim de que sejam informativas no estudo de microarrays. Os principais polimorfismos genéticos associados com LPA/SDRA estáo na quadro 1 e um glossário de termos correntemente utilizados está no quadro 2.

\section{GENES RELACIONADOS À INFLAMAÇÁO, RESPOSTA IMUNE, ESTRESSE OXIDATIVO E CO- AGULAÇÃO}

As citocinas desempenham um papel fundamental na reação inflamatória local e sistêmica em resposta à infecção ou um estado inflamatório. $\mathrm{O}$ fator de necrose tumoral $\alpha$ (FNT- $\alpha$ ) é uma citocina chave na cascata inflamatória e um dos principais mediadores da sepse e LPA/SDRA. O gene que codifica para o FNT- $\alpha$ está localizado no cromossoma 6 próximo a outros genes que codificam outras citocinas e são essenciais para o ciclo celular. ${ }^{(12)}$ Os polimorfismos $-308 \mathrm{G}>\mathrm{A}$ na regiáo promotora do gene do FNT- $\alpha$ e o TNFB1/2 no gene do FNT- $\beta$ associam-se com um aumento na síntese de FNT- $\alpha{ }^{(17)}$ Em um estudo de caso-controle com 441 controles caucasianos e 212 casos admitidos com fatores de risco para LPA/SDRA, os autores encontraram associação entre o alelo -308A e mortalidade em 60 dias, sendo mais pronuncia- 
Quadro 2 - Glossário de termos utilizados em medicina genômica

\begin{tabular}{|c|c|}
\hline Termo & Significado \\
\hline Alelo & Versão variante de um gene \\
\hline Alu & $\begin{array}{l}\text { Seqüência de DNA composta por cerca de } 200 \text { nucleotídeos reconhecida pela endonuclease de res- } \\
\text { trição } A l u I \text {, que se apresenta muitas vezes repetida de forma dispersa ao longo do genoma humano }\end{array}$ \\
\hline Base nitrogenada & Adeninas $(\mathrm{A})$, timinas $(\mathrm{T})$, citosinas $(\mathrm{C})$ e guaninas $(\mathrm{G})$ \\
\hline cDNA & Segmento de DNA complementar ao RNA mensageiro \\
\hline Codificação & Leitura dos códons para a síntese da proteína \\
\hline Codon & Conjunto de três bases nitrogenadas que indica qual aminoácido será incorporado na proteína \\
\hline DNA & $\begin{array}{l}\text { Molécula formada por duas cadeias de nucleotídeos (pentose, fosfato e base nitrogenada) organi- } \\
\text { zadas em hélice }\end{array}$ \\
\hline Exon & Seqüência intragênica que, depois de transcrita, permanece no mRNA \\
\hline Gene & Segmento de DNA que transcreve em um RNA \\
\hline Gene candidato & Gene cujas alteraçôes ou cujas variantes podem conferir susceptibilidade a determinada característica \\
\hline Genotipagem & Determinação do tipo de alelos/genes que o indivíduo herdou para certo lócos \\
\hline Genótipo & conjunto diplóide de alelos/genes que o indivíduo herdou para certo lócus \\
\hline Haplótipo & conjunto haplóide de variantes genéticas que o indivíduo herdou para certo lócos \\
\hline Heterozigoto & Condição em que o zigoto foi formado por dois alelos/genes diferentes \\
\hline Homozigoto & Condição em que o zigoto foi formado por dois alelos/genes idênticos \\
\hline Locus & Lugar específico onde se localiza um gene (ou porção de um gene) no cromossomo \\
\hline Microarrays & $\begin{array}{l}\text { Arranjos de seqüência de DNA capazes de identificar genes que estão sendo expressos (transcritos) } \\
\text { dependendo do tecido ou do estado fisiológico ou de desenvolvimento de órgáos e de indivíduos }\end{array}$ \\
\hline mRNA (RNA mensageiro) & $\begin{array}{l}\text { Molécula formada por uma cadeia de nucleotídeo (pentose, fosfato e base nitrogenada) sintetizada } \\
\text { a partir de um gene }\end{array}$ \\
\hline Nucleotídeo & $\begin{array}{l}\text { Monômero formador dos ácidos nucléicos (DNA e RNA) constituído por pentose, fosfato e base } \\
\text { nitrogenada }\end{array}$ \\
\hline PCR (Polymerase Chain Reaction) & Tecnologia que permite sintetizar cópias de segmentos de DNA pelo uso de ciclos de temperatura \\
\hline Polimorfismo & $\begin{array}{l}\text { Formas variadas de uma seqüência de DNA ocupante de um mesmo lócos. Consideram-se poli- } \\
\text { mórficas as formas que já se estendem por, pelo menos, } 1 \% \text { da populaçấo. As variantes polimór- } \\
\text { ficas podem ser de tamanho ou de seqüência }\end{array}$ \\
\hline Promotor & Seqüência de DNA que antecede a regiáo que será transcrita e promove a transcrição \\
\hline $\begin{array}{l}\text { SNP (Single Nucleotide } \\
\text { Polymorphism) }\end{array}$ & $\begin{array}{l}\text { Substituição de um único nucleotídeo em determinada posição que se estende por, pelo menos, } \\
1 \% \text { da populaçấo }\end{array}$ \\
\hline Transcrição & Processo pelo qual um gene é usado como molde para a síntese de moléculas de RNA \\
\hline
\end{tabular}

da esta associação entre os pacientes com idade inferior a 67 anos. $\mathrm{O}$ polimorfismo TNFB não mostrou associação com a mortalidade. ${ }^{(17)}$

A associação entre interleucina (IL)-6, uma potente citocina pró-inflamatória, e LPA/SDRA mostra resultados conflitantes, pelo menos no que se refere ao $S N P-174 \mathrm{G}>\mathrm{C}$. Embora alguns autores tenham encontrado associação entre o gene da IL-6 com a suscetibilidade à LPA/SDRA, ${ }^{(18)}$ outros não confirmaram este achado. ${ }^{(19)}$ Entretanto, estudando 20 SNPs no gene da IL-6, Flores et al. ${ }^{(19)}$ encontraram associação entre o haplótipo GGGAAC e a ocorrência de LPA/SDRA.

A IL-8 é um dos importantes mediadores na patogênese da LPA/SDRA. No lavado bronco-alveolar (LBA) de pacientes com SDRA, os níveis de IL-8 estáo significativamente elevados e mostram associaçáo com o desenvolvimento da
SDRA na população de risco. ${ }^{(20)}$ Em estudo de associação entre o $S N P-251 \mathrm{~A}>\mathrm{T}$ do gene da IL-8 e LPA/SDRA, os portadores do alelo -251A apresentaram maior síntese de IL-8 e os pacientes com o genótipo -251AA necessitaram de ventilação mecânica $(\mathrm{VM})$ por tempo significativamente maior. ${ }^{(21)}$

O genótipo -1082GG do SPN-1082 no promotor do gene da IL-10 associa-se a reduçấo de risco de insuficiência respiratória aguda em pacientes com trauma. ${ }^{(22)}$ Em pacientes com SDRA, o genótipo -1082GG associa-se à menor gravidade na admissão, menor grau de disfunção orgânica e mortalidade. $^{(23)}$

A MBL (mannose binding lectin) é uma proteína de reconhecimento padrão, importante na ativação do sistema complemento e opsoninas indutoras de fagocitose. ${ }^{(24)}$ A proteína MBLé codificada pelo gene MBL-2 (mannose bidinglectin-2), 
situado no cromossomo 10. Os níveis de MBL circulantes são dependentes de três SNPs nos codons 52 (rs5030737), 54 (rs1800450) e 57 (rs1800451), no exon 1 e um SNP na posição -221 (MBLXY; rs7096202). ${ }^{(25)}$ As variantes alélicas do exon 1 são conhecidas como $\mathrm{D}, \mathrm{B}$ e $\mathrm{C}$, respectivamente, enquanto o alelo selvagem é conhecido como $\mathrm{A}$. As variantes alélicas no exon 1 e o alelo X no polimorfismo MBLXY estão associados com deficiência nos níveis séricos de MBL, em particular os indivíduos homozigotos para as variantes alélicas raras. ${ }^{(26)}$ Um estudo de casos e controles avaliou 212 pacientes caucasianos com SDRA e 442 controles, tendo como hipótese de que o alelo X do polimorfismo MBLXY e as variantes D, $\mathrm{B}$ e $\mathrm{C}$ dos codons 52, 54 e 57 do gene da MBL2 associam-se ao aumento da suscetibilidade e da mortalidade na SDRA. ${ }^{(27)}$ Os pacientes homozigotos para a variante alélica 54B (54BB) tinham maior gravidade na admissão, maior probabilidade de choque séptico e SDRA, em comparação com os heterozigotos e homozigotos para o alelo selvagem. A associação com SDRA foi especialmente marcada nos pacientes com choque séptico. Nos pacientes que desenvolveram SDRA, o genótipo 54BB associou-se a maior número de disfunçôes orgânicas e mortalidade. ${ }^{(27)}$

Entre os mediadores produzidos pelos macrófagos, o macrophage migration inhibitory factor (MIF), é uma citocina pró-inflamatória com importante papel na resposta à endotoxemia. ${ }^{(28)}$ Em amostras de DNA de 506 indivíduos com sepse, LPA induzida pela sepse e controles sadios, não houve correlação entre SNP individuais e sepse ou LPA. Houve associação entre haplótipos localizados na regiáo 3' do gene do MIF e suscetibilidade à sepse e LPA. ${ }^{(28)}$

O fator estimulador de crescimento pré-células B (pré$B$-cell colony-enhancing factor) (PBEF), também conhecido como visfatina, é uma citocina originalmente isolada em linfócitos. ${ }^{(29)} \mathrm{A}$ expressão do PBEF está aumentada em modelos animais e em humanos com LPA e seus níveis estáo aumentados no LBA de animais de humanos com LPA. ${ }^{(30)} \mathrm{O}$ papel da genética para o desenvolvimento de SDRA foi estudado em 787 pacientes com risco e em 375 com a síndrome instalada. A variaçáo polimórfica $-1001 \mathrm{~T}>\mathrm{G}$ do gene $\mathrm{PBEF}$ associouse com risco aumentado para suscetibilidade e mortalidade, enquanto o polimorfismo $-1543 \mathrm{C}>\mathrm{T}$ associou-se a melhores desfechos. ${ }^{(31)}$

O fator nuclear $\kappa-B(N F-\kappa B)$ tem papel importante na resposta inflamatória, regulando a expressão de inúmeros genes de mediadores da inflamação, como moléculas de adesão e citocinas. Em células não estimuladas, o NF- $\kappa-B$ encontrase no citoplasma em sua forma inativa, o I- $\kappa B$ (NFKBIA). Quando estimulado, o NFKBIA é rapidamente degradado e translocado para o núcleo visando ativar a expressão de genes alvo. ${ }^{(32)} \mathrm{O}$ haplótipo GTC do gene NFKBIA associa-se com aumento do risco de SDRA em caucasianos, particularmente em pacientes do sexo masculino e lesão pulmonar primária. (33) Um polimorfismo de inserção/deleção (ID) no promotor do gene NFKB1 afeta a gravidade da SDRA sem influenciar na mortalidade. ${ }^{(34)}$

Os radicais livres de oxigênio $\left(\mathrm{RLO}_{2}\right)$ são produzidos em situaçóes em que ocorra isquemia-reperfusão. Para protegerse dos efeitos deletérios destas moléculas as células produzem antioxidantes que, ao interagirem com os $\mathrm{RLO}_{2}$, geram produtos menos ativos. A superóxido dismutase (SOD) é uma das enzimas antioxidantes envolvidas na proteçáo celular. ${ }^{(35)} \mathrm{A}$ SOD extra-celular (EC) é expressa em grande quantidade nos pulmôes, desempenhando um papel importante na regulação da inflamação e do estresse oxidativo. Em humanos, o gene da SOD localiza-se no cromossomo 4, sendo que um SNP ocorre em uma regiáo codificadora, resultando na troca de uma arginina por uma glicina. $\mathrm{O}$ produto final é um aumento de 10 vezes nos níveis de SOD-EC. ${ }^{(36)}$ Além desta alteração, pelo menos outras três já foram observadas como tendo importantes efeitos sobre o fenótipo dos pacientes com LPA: em uma população de 157 pacientes de etnia caucasiana, portadores do haplótipo GCCT mostraram uma redução na inflamação pulmonar, no tempo de VM e na mortalidade. ${ }^{(36)}$

A uroquinase é uma serina protease que cliva o plasminogênio para formar plasmina, um mediador potente da fibrinólise. (37) $\mathrm{O}$ gene da uroquinase está localizado no cromossomo 10. Em um estudo de associação, foram analisados $98 \%$ de todos os haplótipos deste gene. O haplótipo CGCCCC mostrou associação com mortalidade em 60 dias e dias livres de VM, sendo um fator de risco para desfechos desfavoráveis. ${ }^{(38)}$

A via da proteína $\mathrm{C}$ previne a ativaçáo exagerada da cascata de coagulação do sangue, protegendo contra a formação inadvertida de coágulos pela inativação dos fatores Va e VIIIa. Um $S N P$ no fator $\mathrm{V}$ de Leiden altera a atividade normal desta via natural de anticoagulação por tornar o fator Va resistente à inativação pela proteína $\mathrm{C}$ ativada. Em pacientes com SDRA, os indivíduos heterozigotos (Arg/Gln; portadores do alelo que codifica para o resíduo Gln) para o genótipo do fator $\mathrm{V}$ de Leiden apresentam melhor sobrevida em 30 do que os homozigotos (Arg/Arg). ${ }^{(39)}$

\section{GENES RELACIONADOS À PERMEABILIDA- DE E TÔNUS VASCULAR, ATIVIDADE DE FIBRO- BLASTOS E TENSÃO SUPERFICIAL}

Como LPA/SDRA cursam com alteraçóes na permeabilidade, que associadas a alteraçóes no tônus vascular, no reparo da lesáo pulmonar e na capacidade de manter os alvéolos abertos, caracterizam um grave quadro de insuficiência respiratória, os genes de moléculas envolvidas nesses processos têm 
importante papel. A enzima de conversão da angiotensina (ECA) é uma metalopeptidase zinco-dependente cuja principal função é a conversão da angiotensina I em angiotensina II e a inativação de bradicinina. O gene ECA encontra-se no locus $17 \mathrm{q} 23$ e contém 26 exons. O polimorfismo mais conhecido deste gene consiste na presença (alelo I) ou ausência (alelo D) de uma sequência Alu de 287 pares de bases próximo à extremidade 3' do intron 16. Essa variação polimórfica produz três possíveis genótipos: II, ID e DD. ${ }^{(40)}$ Três estudos mostraram associação entre este polimorfismo e mortalidade na SDRA, dois em pacientes caucasianos ${ }^{(41,42)}$ e outro em pacientes de raça amarela. ${ }^{(43)}$ Recentemente, estudo conduzido na Espanha, não mostrou associação entre este polimorfismo e suscetibilidade ou mortalidade na SDRA, ${ }^{(44)}$ achado corroborado por nosso grupo. ${ }^{(40)}$ Outro polimorfismo na região promotora do gene do angiotensinogênio (AGT) (-6)A/G, o qual se relaciona diretamente com a açáo da ECA, não mostrou associação com suscetibilidade ou mortalidade. ${ }^{(42)}$

O fator de crescimento do endotélio vascular (vascular endothelial growth factor - VEGF) é um potente vasodilatador. (40) $\mathrm{O}$ VEGF apresenta um polimorfismo 936C $>\mathrm{T}$, o qual foi estudado para determinar sua participação na suscetibilidade genética da SDRA. Um estudo de associação avaliou com 137 indivíduos normais e 220 pacientes submetidos à VM prospectivamente. Os pacientes em VM foram agrupados em: com risco para SDRA ( $\mathrm{n}=103)$ e com SDRA $(\mathrm{n}=112)$, e cinco foram excluídos da análise. Os genótipos 936CT e 936TT foram significativamente mais freqüentes nos pacientes com SDRA do que no grupo normal $(\mathrm{p}=0,02)$ e no grupo de risco para SDRA ( $p=0,03$ ). O alelo 936T ocorreu com maior freqüência no grupo com SDRA ( $\mathrm{p}=0,04)$ em comparaçáo com os outros grupos. Não houve diferença na mortalidade entre o grupo de risco para SDRA e o grupo com SDRA, entretanto, os pacientes com SDRA e genótipo 936CT e 936TT apresentaram o escore Acute Physiologic Chronic Health Evaluation III (APA$\mathrm{CHE}$ III) maior do que os homozigotos $936 \mathrm{CC}(\mathrm{p}<0,05)$. Estes achados sugerem que existe associaçáo do alelo 936T com suscetibilidade para SDRA e distúrbios fisiológicos, conforme evidenciado pelo escore APACHE III.(45)

A proteína B do surfactante (SP-B) é uma proteína hidrofóbica com propriedades cruciais para o funcionamento do surfactante. O gene codificante da SP-B localiza-se no braço curto do cromossomo 2, contendo aproximadamente 9.500 pares de bases $(\mathrm{pb}){ }^{(46)} \mathrm{Um}$ polimorfismo localizado no intron 4 desse gene está associado com a suscetibilidade à SDRA. ${ }^{(47)}$ Em uma população de risco para SDRA após a estratificação de acordo com o sexo e ajustes para fatores de confusão, a variaçáo polimórfica do gene SP-B mostrou associação com a suscetibilidade para SDRA primária em mulheres, porém, não em homens. ${ }^{(46)}$

\section{GENES RELACIONADOS À QUIMIOTAXIA E MOBILIDADE CELULAR}

As células claras 16 (CC16) são um potente inibidor da quimiotaxia dos neutrófilos e da atividade da fosfolipase $\mathrm{A}_{2}$. Um estudo de associação com 117 pacientes caucasianos com SDRA e 373 controles saudáveis não mostrou relação entre o polimorfismo -26G $>$ A e a suscetibilidade à SDRA. ${ }^{(48)}$

A importância do gene da myosin light chain kinase (MYLK) deve-se ao fato de que o mesmo participa na apoptose e na diapedese dos leucócitos, dois eventos essenciais na LPA/SDRA. ${ }^{(49)}$ Em estudo de associação com indivíduos caucasianos em um grupo e afro-americanos em outro, Gao et al. ${ }^{(50)}$ identificaram risco para a ocorrência de LPA/SDRA induzida por sepse nos portadores de haplótipos específicos na região 5 ' em ambos os grupos e na região 3' apenas nos afro-americanos. A ocorrência de LPA após trauma também é influenciada por polimorfismos neste gene, particularmente em afro-americanos. ${ }^{(49)}$

\section{O PAPEL DA GENÔMICA NA PRÁTICA CLÍNICA}

O emprego das informaçóes derivadas de estudos de associação, como todo método novo, deve ser feito com parcimônia. Para o médico, os resultados iniciais desses estudos devem ser confirmados em populaçóes similares e por diferentes grupos de pesquisadores. ${ }^{(51)}$ Muitas vezes um determinado $S N P$ pode não mostrar associação, o que não deve afastar seu envolvimento na doença, pois a abordagem baseada em haplótipos usando múltiplos marcadores genéticos pode identificar associação. ${ }^{(52)}$ Os objetivos da epidemiologia genética na LPA/ SDRA são identificar genes que tenham influência na suscetibilidade, intensidade da inflamação pulmonar, necessidade de determinados tipos de tratamento, prognóstico e mortalidade.

Um aspecto de fundamental importância na valorização dos estudos de associação genética é sua qualidade. Isto pode ser avaliado considerando-se: (1) tamanho da amostra; (2) presença de grupo controle adequado; (3) estar em equilíbrio de Hardy-Weinberg; (4) casos bem definidos para a doença em estudo; (5) o primer utilizado para o sequenciamento deve ser passível de reprodução; (6) investigador que faz a análise genética não deve conhecer a condição clínica do indivíduo (cegamento); (7) o estudo deve ter poder estatístico; (8) as genotipagens devem ser replicadas. ${ }^{(53)}$

\section{CONSIDERAÇÓES FINAIS}

O uso da genética para identificar de outro modo populaçóes de risco para o desenvolvimento de LPA/SDRA abre um novo campo na medicina. A busca para melhorar o cui- 
dado do paciente crítico utilizando esta tecnologia envolve inicialmente a identificação de genes candidatos, o que pode ser feito no âmbito experimental ou clínico. O segundo passo é a realização de estudos de associação que sejam robustos, tenham qualidade e sejam passíveis de reprodução.

A partir dessas informaçóes poderemos estabelecer estratégias de cuidados desde a identificação precoce de populações de risco até a seleção de terapias individualizadas.

\section{ABSTRACT}

Acute lung injury and its most severe presentation, acute respiratory distress syndrome, are a common denominator for several diseases which can lead to exaggerated lung inflammation. In the last years this variability has been ascribed, at least partially, to genetic issues. This study aims to review the role of the main genes involved in acute lung injury and acute respiratory distress syndro- me susceptibility, morbidity and mortality. By search on PubMed and LiLACS databases, using the key words acute lung injury, acute respiratory distress syndrome and adult acute respiratory distress syndrome in combination with genetic polymorphisms, 69 papers were selected, from which 38 were included in this review. Were also considered relevant articles extracted from the reference lists in the articles selected from the databases. Genetic polymorphisms are gene variations in at least $1 \%$ population. These gene variations may influence the inflammatory response mediators' expression, directly affecting the susceptibility to acute lung injury, the intensity of lung parenchyma inflammation, the development clinical course and outcome. Association studies reproducible in large populations will definitely allow genomics to be included into the diagnostic and therapeutic armamentarium for acute lung injury/acute respiratory distress syndrome patients.

Keywords: Lung injury; Respiratory distress syndrome, adult; Polymorphism, genetic

\section{REFERÊNCIAS}

1. Ware LB, Matthay MA. The acute respiratory distress syndrome. N Engl J Med. 2000;342(18):1334-49. Review.

2. Günther A, Walmrath D, Grimminger F, Seeger W. Pathophysiology of acute lung injury. Semin Respir Crit Care Med. 2001;22(3):247-58.

3. Rubenfeld GD, Caldwell E, Peabody E, Weaver J, Martin DP, Neff M, et al. Incidence and outcomes of acute lung injury. N Engl J Med. 2005;353(16):1685-93.

4. Luhr OR, Antonsen K, Karlsson M, Aardal S, Thorsteinsson A, Frostell CG, Bonde J. Incidence and mortality after acute respiratory failure and acute respiratory distress syndrome in Sweden, Denmark, and Iceland. The ARF Study Group. Am J Respir Crit Care Med. 1999;159(6):184961.

5. Hughes M, MacKirdy FN, Ross J, Norrie J, Grant IS; Scottish Intensive Care Society. Acute respiratory distress syndrome: an audit of incidence and outcome in Scottish intensive care units. Anaesthesia. 2003;58(9):838-45.

6. Bersten AD, Edibam C, Hunt T, Moran J; The Australian and New Zealand Intensive Care Society Clinical Trials Group. Incidence and mortality of acute lung injury and the acute respiratory distress syndrome in three Australian States. Am J Respir Crit Care Med. 2002;165(4):443-8.

7. Cartin-Ceba R, Gong MN, Gajic O. Genetic susceptibility in ALI/ARDS: what have we learned? In: Yearbook Intensive Care EmergencyMedicine. New York: Year Book; 2008. p. 13-23.

8. Calfee CS, Eisner MD, Ware LB, Thompson BT, Parsons PE, Wheeler AP, Korpak A, Matthay MA; Acute Respiratory Distress Syndrome Network, National Heart, Lung, and Blood Institute. Trauma-associated lung injury differs clinically and biologically from acute lung injury due to other clinical disorders. Crit Care Med. 2007;35(10):224350.

9. Villar J, Siminovitch KA. Molecular intensive care medicine. Intensive Care Med. 1999;25(7):652-61.

10. dos Santos CC, Okutani D, Hu P, Han B, Crimi E, He $\mathrm{X}$, et al. Differential gene profiling in acute lung injury identifies injury-specific gene expression. Crit Care Med. 2008;36(3):855-65.

11. Copland IB, Kavanagh BP, Engelberts D, McKerlie C, Belik J, Post M. Early changes in lung gene expression due to high tidal volume. Am J Respir Crit Care Med. 2003;168(9):1051-9.

12. Villar J. Genetics and the pathogenesis of adult respiratory distress syndrome. Curr Opin Crit Care. 2002;8(1):1-5.

13. Lander ES, Linton LM, Birren B, Nusbaum C, Zody $\mathrm{MC}$, Baldwin J, et al, International Human Genome Sequencing Consortium. Initial sequencing and analysis of the human genome. Nature. 2001;409(6822):860921. Erratum in: Nature 2001;412(6846):565. Nature 2001;411(6838):720. Szustakowki, J [corrected to Szustakowski, J].

14. Burke W. Genomics as a probe for disease biology. N Engl J Med. 2003;349(10):969-74.

15. Christie JD. Microarrays. Crit Care Med. 2005;33;(12 Suppl):S449-52.

16. Grigoryev DN, Finigan JH, Hassoun P, Garcia JG. Science review: searching for gene candidates in acute lung injury. Crit Care. 2004;8(6):440-7.

17. Gong MN, Zhou W, Williams PL, Thompson BT, Pothier L, Boyce P, Christiani DC. -308GA and TNFB polymorphisms in acute respiratory distress syndrome. Eur Respir J. 2005;26(3):382-9. 
18. Marshall RP, Webb S, Hill MR, Humphries SE, Laurent GJ. Genetic polymorphisms associated with susceptibility and outcome in ARDS. Chest. 2002;121(3 Suppl):68S69S.

19. Flores C, Ma SF, Maresso K, Wade MS, Villar J, Garcia JG. IL6 gene-wide haplotype is associated with susceptibility to acute lung injury. Transl Res. 2008;152(1):11-7.

20. Mukaida N. Pathophysiological roles of interleukin-8/ CXCL8 in pulmonary diseases. Am J Physiol Lung Cell Mol Physiol. 2003;284(4):L566-77.

21. Hildebrand F, Stuhrmann M, van Griensven M, Meier S, Hasenkamp S, Krettek C, Pape HC. Association of IL-8251A/T polymorphism with incidence of Acute Respiratory Distress Syndrome (ARDS) and IL-8 synthesis after multiple trauma. Cytokine. 2007;37( 3):192-9.

22. Schroeder O, Schulte KM, Schroeder J, Ekkernkamp A, Laun RA. The -1082 interleukin-10 polymorphism is associated with acute respiratory failure after major trauma: a prospective cohort study. Surgery. 2008;143(2):233-42.

23. Gong MN, Thompson BT, Williams PL, Zhou W, Wang MZ, Pothier L, Christiani DC. Interleukin-10 polymorphism in position -1082 and acute respiratory distress syndrome. Eur Respir J. 2006;27(4):674-81.

24. Gadjeva M, Takahashi K, Thiel S. Mannan-binding lectin - a soluble pattern recognition molecule. Mol Immunol. 2004;41(2-3):113-21.

25. Turner MW. The role of mannose-binding lectin in health and disease. Mol Immunol. 2003;40(7):423-9.

26. Garred P, Pressler T, Madsen HO, Frederiksen B, Svejgaard A, Høiby N, et al. Association of mannose-binding lectin gene heterogeneity with severity of lung disease and survival in cystic fibrosis. J Clin Invest. 1999;104(4):431-7.

27. Gong MN, Zhou W, Williams PL, Thompson BT, Pothier L, Christiani DC. Polymorphisms in the mannose binding lectin-2 gene and acute respiratory distress syndrome. Crit Care Med. 2007;35(1):48-56.

28. Gao L, Flores C, Fan-Ma S, Miller EJ, Moitra J, Moreno $\mathrm{L}$, et al. Macrophage migration inhibitory factor in acute lung injury: expression, biomarker, and associations. Transl Res. 2007;150(1):18-29.

29. Luk T, Malam Z, Marshall JC. Pre-B cell colony-enhancing factor (PBEF)/visfatin: a novel mediator of innate immunity. J Leukoc Biol. 2008;83(4):804-16.

30. Ye SQ, Simon BA, Maloney JP, Zambelli-Weiner A, Gao L, Grant A, et al. Pre-B-cell colony-enhancing factor as a potential novel biomarker in acute lung injury. Am J Respir Crit Care Med. 2005;171(4):361-70.

31. Bajwa EK, Yu CL, Gong MN, Thompson BT, Christiani DC. Pre-B-cell colony-enhancing factor gene polymorphisms and risk of acute respiratory distress syndrome. Crit Care Med. 2007;35(5):1290-5.

32. Christman JW, Sadikot RT, Blackwell TS. The role of nuclear factor-kappa B in pulmonary diseases. Chest. 2000;117(5):1482-7. Review.
33. Zhai R, Zhou W, Gong MN, Thompson BT, Su L, Yu C, et al. Inhibitor kappaB-alpha haplotype GTC is associated with susceptibility to acute respiratory distress syndrome in Caucasians. Crit Care Med. 2007;35(3):893-8.

34. Adamzik M, Frey UH, Rieman K, Sixt S, Beiderlinden M, Siffert W, Peters J. Insertion/deletion polymorphism in the promoter of NFKB1 influences severity but not mortality of acute respiratory distress syndrome. Intensive Care Med. 2007;33(7):1199-203.

35. Dal Pizzol F. Lesão por reperfusão e radicais livres de oxigênio. In: Dias FS, Rezende E, Mendes CL, Réa-Neo A. Choque circulatório. Rio de Janeiro: Revinter; 2008. p. 23-35.

36. Arcaroli JJ, Hokanson JE, Abraham E, Geraci M, Murphy JR, Bowler RP, et al. Extracellular superoxide dismutase haplotypes are associated with acute lung injury and mortality. Am J Respir Crit Care Med. 2009;179(2 ):105-12.

37. Idell S. Endothelium and disordered fibrin turnover in the injured lung: newly recognized pathways. Crit Care Med. 2002;30(5 Suppl):S274-80.

38. Arcaroli J, Sankoff J, Liu N, Allison DB, Maloney J, Abraham E. Association between urokinase haplotypes and outcome from infection-associated acute lung injury. Intensive Care Med. 2008;34(2):300-7.

39. Adamzik M, Frey UH, Riemann K, Sixt S, Lehmann N, Siffert W, Peters J. Factor V Leiden mutation is associated with improved 30-day survival in patients with acute respiratory distress syndrome. Crit Care Med. 2008;36(6):1776-9.

40. Dias FS. Polimorfismo I/D do gene ECA em pacientes com síndrome da angústia respiratória aguda (SDRA) [tese]. Porto Alegre: Faculdade de Biociências da Pontifícia Universidade Católica do Rio Grande do Sul; 2007.

41. Marshall RP, Webb S, Bellingan GJ, Montgomery HE, Chaudhari, McAnulty RJ, et al. Angiotensin converting enzime insertion/deletion polymorphism is associated with susceptibility and outcome in acute respiratory distress syndrome. Am J Respir Crit Care Med. 2002;166(5):64650.

42. Adamzik M, Frey U, Sixt S, Knemeyer L, Beiderlinden M, Peters J, Siffert W. ACE I/D but not AGT (-6)A/G polymorphism is a risk factor for mortality in ARDS. Eur Resp J. 2007;29(3):482-8.

43. Jerng JS, Yu CJ, Wang HC, Chen KY, Cheng SL, Yang PC. Polymorphism of the angiotensin-converting enzyme gene affects the outcome of acute respiratory distress syndrome. Crit Care Med. 2006;34(4):1001-6.

44. Villar J, Flores C, Pérez-Méndez L, Maca-Meyer N, Espinosa E, Blanco J, Sangüesa R, Muriel A, Tejera P, Muros M, Slutsky AS; GRECIA group; GEN-SEP group. Angiotensin-converting enzyme insertion/deletion polymorphism is not associated with susceptibility and outcome in sepsis and acute respiratory distress syndrome. Intensive Care Med. 2008;34(3):488-95. 
45. Medford AR, Kenn LJ, Bidwell JL, Millar AB. Vascular endothelial growth factor gene polymorphism and acute respiratory distress syndrome. Thorax. 2005;60(3):244-8.

46. Gong MN, Wei Z, Xu LL, Miller DP, Thompson BT, Christiani DC. Polymorphism in the surfactant protein-B gene, gender, and the risk of direct pulmonary injury and ARDS. Chest. 2004;125(1):203-11.

47. Lin Z, Pearson C, Chinchilli V, Pietschmann SM, Luo J, Pison U, Floros J. Polymorphisms of human SP-A, SP-B, and SP-D genes: association of SP-B Thr13Ile with ARDS. Clin Genet. 2000;58(3):181-91.

48. Frerking I, Sengler C, Günther A, Walmrath HD, Stevens P, Witt $\mathrm{H}$, et al. Evaluation of the $-26 \mathrm{G}>\mathrm{A}$ CC16 polymorphism in acute respiratory distress syndrome. Crit Care Med. 2005;33(10):2404-6.

49. Christie JD, Ma SF, Aplenc R, Li M, Lanken PN, Shah
$\mathrm{CV}$, et al. Variation in the myosin light chain kinase gene is associated with development of acute lung injury after major trauma. Crit Care Med. 2008;36(10):2794-800.

50. Gao L, Grant A, Halder I, Brower R, Sevransky J, Maloney JP, et al. Novel polymorphisms in the myosin light chain kinase gene confer risk for acute lung injury. Am J Respir Cell Moll Biol. 2006;34(4):487-95.

51. Christensen K, Murray JC. What genome-wide association studies dan do for medicine. $\mathrm{N}$ Engl J Med. 2007;356(11):1094-7.

52. Christie J. Genetic epidemiology of acute lung injury: choosing the right candidate genes is the first step. Crit Care. 2004;8(6):411-3.

53. Clark MF, Baudouin SV. A systematic review of the quality of genetic association studies in human sepsis. Intensive Care Med. 2006;32(11):1706-12. 